\title{
Mental health and HIV sexual risk behaviour among University of Limpopo students
}

\author{
S Pengpid, ${ }^{1,2} \mathrm{DrPH} ;$ K Peltzer, ${ }^{1,2,3} \mathrm{PhD} ; \mathbf{L}$ Skaal, ${ }^{4} \mathrm{DrPH}$ \\ ${ }^{1}$ ASEAN Institute for Health Development, Madidol University, Salaya, Phutthamonthon, Nakhonpathom, Thailand \\ ${ }^{2}$ Department of Psychology, University of Limpopo, Turfloop, Limpopo, South Africa \\ ${ }^{3}$ HIV/AIDS, STI and TB (HAST) Research Programme, Human Sciences Research Council, Pretoria, Gauteng, South Africa \\ ${ }^{4}$ Department of Health Systems and Policy, University of Limpopo, Pretoria, Gauteng, South Africa
}

Corresponding author: K Peltzer (kpeltzer@hsrc.ac.za)

\begin{abstract}
Background. Little attention has been paid to the role of poor mental health among young people with regard to HIV risk behaviour and HIV prevention in Africa.

Objective. To determine the association between mental health, substance use and HIV sexual risk behaviour among a sample of university students in South Africa.

Methods. A cross-sectional survey was conducted among undergraduate students who were recruited conveniently from public campus venues at the University of Limpopo Medical University of Southern Africa (Medunsa) campus. The sample included 722 university students (57.6\% men and $42.4 \%$ women) with a mean age of 21.7 years (standard deviation \pm 8.8 ).

Results. Of the 722 students, 39.5\% reported depression, 23.4\% screened positive for post-traumatic stress disorder (PTSD), 22\% reported hazardous or harmful alcohol use, $33 \%$ reported $\geq 2$ sexual partners in the past 12 months, $50 \%$ reported inconsistent condom use, $46 \%$ reported unknown HIV status of a sexual partner and 20\% reported alcohol use in the context of sex in the past 3 months. In multivariate analysis, HIV risk behaviour was associated with, among men, hazardous or harmful alcohol use and having screened positive for PTSD, and among women, being in the 4 th or more year of study and current cannabis use.

Conclusion. Poor mental health, including substance use, was found to be associated with HIV risk behaviour. Co-ordinated mental health and sexual and reproductive health services that meet the needs of university students would be desirable.
\end{abstract}

S Afr J Psych 2013;19(2):25-30. DOI:10.7196/SAJP.415

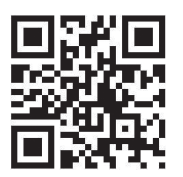

In the last national population-based survey in South Africa (SA) in 2008, HIV prevalence was estimated at $10.5 \%, 17.4 \%$ for women and $3.3 \%$ for men among young people aged 18 - 24 years. ${ }^{[1]}$ Based on antenatal data, the prevalence was $12.0 \%$ among 15 - 24 -year-olds in $2010 .{ }^{[2]}$ Poor mental health is a major cause of morbidity in middleincome countries, with depression constituting the heaviest disease burden. ${ }^{[3]}$ The HIV epidemic contributes to increased depression rates both in persons who live with $\mathrm{HIV}^{[4]}$ and those indirectly affected by HIV/AIDS. ${ }^{[5]}$ Several reviews of the general population indicate a possible relationship between poor mental health, including substance use, and HIV risk behaviour, such as multiple sexual partners and unprotected sex. ${ }^{[6-13]}$

Studies conducted among university students found that anxiety, ${ }^{[14]}$ depression, ${ }^{[14,15]}$ psychological distress, ${ }^{[15]}$ alcohol use, ${ }^{[15-20]}$ drug use, ${ }^{[19,20]}$ and traumatic experiences ${ }^{[21]}$ (in particular childhood abuse, physical abuse, and especially sexual abuse ${ }^{[22]}$ ) were associated with various forms of HIV risk behaviour. Currently, there are not sufficient data on university students regarding the association between mental disorders, substance use and HIV sexual risk behaviour within the SA context.

We therefore aimed to determine the association between mental health, substance use and HIV sexual risk behaviour among undergraduate students of the University of Limpopo Medical University of Southern Africa (Medunsa) campus.

\section{Methods}

\section{Sample and procedure}

A cross-sectional survey design was used. An anonymous, selfadministered questionnaire was used to collect data. Undergraduate students from the Medunsa campus where recruited into the study as they were entering 2 public venues (tents erected between lecture halls and campus residences). A student health promotion study had previously been advertised on the campus for university students. The study protocol was approved by the University of Limpopo Medunsa Research and Ethics Committee. A convenience sample of 732 undergraduate students participated in the survey. After eliminating unusable or incomplete questionnaires, analyses presented in this paper were conducted on a sample of 722 participants.

\section{Measures}

\section{Traumatic experiences}

Participants were asked if they had ever been hit by a sexual partner; forced to have sex; physically abused as a child; sexually abused as a child; or been diagnosed as HIV-positive. Traumatic experience items were coded as yes/no. ${ }^{[23]}$ 


\section{Post traumatic stress disorder (PTSD)}

A 7 -item screener $(\alpha=0.77)$ was used to identify PTSD symptoms that the respondents had experienced in the preceding month. ${ }^{[23,24]}$ Items asked whether the respondent had experienced difficulties related to a traumatic experience (e.g. 'Did you begin to feel more isolated and distant from other people?', 'Did you become jumpy or get easily startled by ordinary noises or movements?'). Consistent with epidemiological evidence, participants who answered at least 4 of the questions affirmatively were considered to have a positive screen for PTSD. ${ }^{[23,24]}$

\section{Depressive symptoms}

We assessed depressive symptoms using the 10-item version of the Center for Epidemiologic Studies Depression Scale (CES-D). ${ }^{[25]}$ While the CES-D 10-item survey has not been directly compared with clinical diagnosis of major depression, the CES-D 20-item survey has been reported to average a sensitivity of $80 \%$ and a specificity of $70 \%$ compared with formal diagnostic interview. ${ }^{[26]}$ In accordance with Andresen et al., ${ }^{[25]}$ the possible range of the 10 -item scale is 0 - 30, and a cut-off score of $\geq 10$ indicates significant depressive symptoms. The Cronbach's a reliability coefficient of this 10 -item scale was 0.72 in this study.

\section{Alcohol consumption}

The 10-item alcohol use disorders identification test (AUDIT) ${ }^{[27]}$ assesses alcohol consumption level (3 items), symptoms of alcohol dependence (3 items), and problems associated with alcohol use (4 items). Heavy episodic drinking is defined as the consumption of $\geq 6$ standard drinks ( $\geq 10 \mathrm{~g}$ alcohol) on a single occasion. ${ }^{[27]}$ In SA a standard drink is $12 \mathrm{~g}$ alcohol. Because AUDIT is reported to be less sensitive at identifying risk drinking in women, ${ }^{[28]}$ the cut-off point of binge drinking for women (4 units) was 1 unit less than for men ( 5 units), as recommended by Freeborn et al. ${ }^{[28]}$ Responses to items in the AUDIT are rated on a 4-point Likert scale from 0 to 4 , for a maximum score of 40 points. Higher AUDIT scores indicate more severe levels of risk; scores of $\geq 8$ indicate a tendency to problematic drinking or hazardous or harmful drinking. ${ }^{[27]}$ Cronbach's a for the AUDIT in this sample was 0.91 , indicating excellent reliability. Hazardous drinking is defined as a quantity or pattern of alcohol consumption that places a person at risk for adverse health events, while harmful drinking is defined as alcohol consumption that results in adverse events (e.g. physical or psychological harm). ${ }^{[29]}$

\section{Tobacco use}

Two questions were asked about the use of tobacco products: (i) Do you currently use one or more of the following tobacco products: cigarettes, snuff, chewing tobacco, cigars, etc.? Response options were 'yes' or 'no'. (ii) In the past month, how often have you used one or more of the following tobacco products: cigarettes, snuff, chewing tobacco, cigars, etc.? Response options were 'once or twice', 'weekly', 'almost daily' and 'daily'.

\section{Cannabis use}

Cannabis use was assessed using 2 items: use in the preceding 12 months and use in the preceding 30 days.

\section{HIV risk behaviour index}

An HIV risk behaviour index was developed based on a literature review $^{[23,30,31]}$ and assessed 4 components of HIV risk: number of sexual partners; protected or unprotected sexual intercourse; alcohol use in the context of sex; and awareness of HIV status of sexual partner. HIV risk behaviour, therefore, was assessed with 4 items: number of sexual partners in the past 12 months, condom use consistency in the past 3 months with primary partner, alcohol use in the context of sex in the past 3 months and knowledge of HIV status of main sexual partner. HIV risk behaviour items were dichotomised into (i) $\geq 2$ sexual partners in the past 12 months, (ii) inconsistent (not every time) condom use, (iii) had consumed alcohol in the context of sex, and (iv) unknown HIV status of a sexual partner. All 4 items were added up to form an HIV risk behaviour index, with scores ranging from 0 to 4 . Similar HIV risk behaviour indices have been used previously in SA. ${ }^{[23,30,31]}$ Since there was no normal distribution, the HIV risk behaviour index was dichotomised: $0-1=0 ; 2-4=1$.

\section{Socioeconomic data}

We classified students according to whether they lived on or off campus. Socioeconomic background was assessed by having students rate their family background as 'wealthy' (within the highest $25 \%$ in $\mathrm{SA}$, in terms of wealth), 'quite well off' (within the $50-75 \%$ range for their country), 'not very well off' (within the 25 - 50\% range from SA), or 'quite poor' (within the lowest $25 \%$ in their country). We subsequently divided the students into 'poorer' ('not very well off' and 'quite poor') and 'wealthier' ('wealthy', 'quite well off') categories.

\section{Data analysis}

The data were analysed using SPSS (version 20.0). First, gender differences were analysed for all variables using chi-square tests. Since there were significant gender differences on a number of variables, subsequent models were analysed separately for men and women. Second, logistic-regression analyses were done to identify traumatic experiences that were associated with a positive screen for PTSD and a positive screen for depression in bivariate analysis. ${ }^{[21]}$ Third, logistic regression was used to identify factors that were associated with HIV risk behaviour. Predictor variables were entered in a single step.

\section{Results \\ Sample characteristics}

The sample included 722 university students (57.6\% men and $42.4 \%$ women) with a mean age of 21.7 years ( $\mathrm{SD} \pm 8.8$ ). Most students resided on campus (82.2\%), $44.7 \%$ were first-year students, and 55\% were from a poorer family background; and $22 \%$ were hazardous or harmful alcohol users. A large group of students indicated that they had significant depressive symptoms (39.5\%), 23.4\% screened positive for PTSD, 14.2\% were current (past month) tobacco users and $11.6 \%$ were current cannabis users. Both women and men indicated that they were subjected to partner violence and abuse as a child. Few (1.3\%) indicated that they were HIV-positive. High rates of HIV risk behaviour were reported ( $33 \%$ reported $\geq 2$ sexual partners in the past 12 months, 50\% inconsistent condom use, $46 \%$ unknown HIV status of a sexual partner and $20 \%$ alcohol use in the context of sex in the past 3 months) (Table 1). 
Table 1. Sample characteristics

\begin{tabular}{|c|c|c|c|c|}
\hline Variable & $\begin{array}{l}\text { Total }(N=722) \\
n \%\end{array}$ & $\begin{array}{l}\text { Men }(N=416) \\
n \%\end{array}$ & $\begin{array}{l}\text { Women }(N=306) \\
n \%\end{array}$ & $\chi^{2}$ \\
\hline \multicolumn{5}{|l|}{ Socio-demographics } \\
\hline Age (years), range $18-41$ & $21.7(8.8)$ & & & \\
\hline \multicolumn{5}{|l|}{ Year of study } \\
\hline 1 st & $278(44.7)$ & $136(38.2)$ & $142(53.4)$ & 14.67 \\
\hline $2 \mathrm{nd} / 3 \mathrm{rd}$ & $236(37.9)$ & $148(41.6)$ & $88(33.1)$ & \\
\hline$\geq 4$ th & $108(17.4)$ & $72(20.2)$ & $36(13.5)$ & \\
\hline \multicolumn{5}{|l|}{ Family background } \\
\hline Wealthier & $322(45.0)$ & $165(40.1)$ & $157(51.6)$ & \\
\hline Poorer & $393(55.0)$ & $246(59.9)$ & $147(48.4)$ & $9.33^{\dagger}$ \\
\hline \multicolumn{5}{|l|}{ Substance use } \\
\hline Current cannabis use & $78(11.6)$ & $64(16.5)$ & $14(5.0)$ & $21.00^{*}$ \\
\hline Current tobacco use & $98(14.2)$ & $87(21.9)$ & $11(3.7)$ & $46.04^{*}$ \\
\hline \multicolumn{5}{|l|}{ Mental health } \\
\hline Screened positive for depression & $285(39.5)$ & $152(36.5)$ & $133(43.5)$ & 3.54 \\
\hline Screened positive for PTSD & $169(23.4)$ & $90(21.6)$ & $79(25.8)$ & 1.72 \\
\hline \multicolumn{5}{|l|}{ Traumatic experiences } \\
\hline Ever been hit by a sexual partner & $49(6.9)$ & $23(5.6)$ & $26(8.6)$ & 2.53 \\
\hline Ever been forced to have sex & $72(10.0)$ & $38(9.2)$ & $34(11.3)$ & 0.86 \\
\hline Physically abused as a child & $59(8.2)$ & $27(6.5)$ & $32(10.5)$ & 3.73 \\
\hline Sexually abused as a child & $32(4.5)$ & $6(1.4)$ & $26(8.6)$ & $20.94^{*}$ \\
\hline HIV-positive & $9(1.3)$ & $6(1.4)$ & $3(1.0)$ & 0.29 \\
\hline Inconsistent condom use & $297(50.3)$ & $171(47.4)$ & $126(54.8)$ & 3.09 \\
\hline Alcohol in the context of sex & $122(19.6)$ & $91(24.8)$ & $31(12.2)$ & $15.24^{*}$ \\
\hline Unknown HIV status of sexual partner & $293(45.5)$ & $211(54.5)$ & $82(31.9)$ & $31.85^{\star}$ \\
\hline
\end{tabular}

\section{Predictors of mental health}

Tables 2 and 3 summarise the univariate logistic regression analyses predicting a positive screen for PTSD and depression, respectively. Among men, PTSD was associated with having been physically abused as a child. Depression was associated with reporting intimate partner violence, forced sex and physical child abuse. For women, intimate partner violence, forced sex and physical and sexual child abuse were associated with PTSD. Depression was associated with sexual partner violence.

\section{Predictors of HIV sexual risk behaviour}

In bivariate analyses among men, hazardous or harmful alcohol use, current tobacco use and screening positive for PTSD were associated with HIV risk behaviour, and in multivariate analysis hazardous or harmful alcohol use and screening positive for PTSD were associated with HIV risk behaviour. In bivariate analyses among women, hazardous or harmful alcohol use, current tobacco and cannabis use and being in the 4th or more year of study were associated with HIV risk behaviour, and in multivariate analysis being in the fourth or more year of study and current cannabis use were associated with HIV risk behaviour.

\section{Discussion}

Among a sample of SA university students, this study found a high prevalence of poor mental health (depression and PTSD symptoms, and substance use), and high HIV risk behaviour (multiple sexual partners, unprotected sex, alcohol in the context of sex and unknown HIV status of a sexual partner). The prevalence of depression, PTSD and hazardous or harmful use was similar to other studies in $\mathrm{SA},{ }^{[32]}$ the prevalence of HIV risk behaviour ( $\geq 2$ sexual partners in the past 12 months and inconsistent condom use) seemed to be higher than in a large recent youth survey (18 - 24-year-olds) in SA, ${ }^{[33]}$ and the 


\section{ARTICLE}

Table 2. Logistic regression analyses predicting a positive screen for PTSD

\begin{tabular}{|c|c|c|c|c|}
\hline \multirow[b]{2}{*}{ Event } & \multicolumn{2}{|c|}{$\operatorname{Men}(N=416)$} & \multicolumn{2}{|c|}{ Women $(N=306)$} \\
\hline & $n(\%)$ & OR $(95 \% \mathrm{CI})$ & $n(\%)$ & OR $(95 \% \mathrm{CI})$ \\
\hline Ever been hit by a sexual partner & $4(17.4)$ & $0.74(0.25-2.25)$ & $12(46.2)$ & $2.78(1.23-6.32)^{\ddagger}$ \\
\hline Ever been forced to have sex & $13(34.2)$ & $2.03(0.99-4.14)$ & $19(55.9)$ & $4.59(2.20-9.58)^{*}$ \\
\hline Physically abused as a child & $11(40.7)$ & $2.77(1.24-6.21)^{*}$ & $16(50.0)$ & $3.32(1.57-7.01)^{\dagger}$ \\
\hline Sexually abused as a child & $1(16.7)$ & $0.73(0.08-6.33)$ & $14(53.8)$ & $3.96(1.74-9.00)^{\star}$ \\
\hline HIV-positive & $2(33.3)$ & $1.85(0.33-10.27)$ & $0(0)$ & 0 \\
\hline
\end{tabular}

Table 3. Logistic regression analyses predicting a positive screen for depression

\begin{tabular}{|c|c|c|c|c|}
\hline \multirow[b]{2}{*}{ Event } & \multicolumn{2}{|c|}{ Men $(N=416)$} & \multicolumn{2}{|c|}{ Women $(N=306)$} \\
\hline & $n(\%)$ & OR $(95 \% \mathrm{CI})$ & $n(\%)$ & OR $(95 \% \mathrm{CI})$ \\
\hline Ever been hit by a sexual partner & $15(65.2)$ & $3.46(1.43-8.37)^{\dagger}$ & $12(46.2)$ & $1.11(0.50-2.50)$ \\
\hline Ever been forced to have sex & $22(57.9)$ & $2.61(1.33-5.15)^{\dagger}$ & $20(58.8)$ & $2.70(1.25-5.86)^{\ddagger}$ \\
\hline Physically abused as a child & $18(66.7)$ & $3.86(1.69-8.84)^{*}$ & $14(43.8)$ & $1.52(0.64-3.58)$ \\
\hline Sexually abused as a child & $2(33.3)$ & $0.87(0.16-4.82)$ & $10(38.5)$ & $1.03(0.37-2.86)$ \\
\hline HIV-positive & $3(50.0)$ & $1.76(0.35-8.45)$ & $2(66.7)$ & $2.60(0.23-28.99)$ \\
\hline $\begin{array}{l}\text { OR }=\text { odds ratio; } \mathrm{CI}=\text { confidence interval. } \\
{ }^{*} p<0.001 . \\
t \\
p<0.01 . \\
t^{p}<0.05\end{array}$ & & & & \\
\hline
\end{tabular}

Table 4. Logistic regression analyses predicting HIV risk behaviour

\begin{tabular}{|c|c|c|c|c|}
\hline \multirow[b]{2}{*}{ Factor } & \multicolumn{2}{|c|}{$\operatorname{Men}(N=416)$} & \multicolumn{2}{|c|}{ Women $(N=306)$} \\
\hline & Crude OR $(95 \% \mathrm{CI})$ & Adjusted OR (95\% CI) & Crude OR (95\% CI) & Adjusted OR (95\% CI) \\
\hline \multicolumn{5}{|l|}{ Socio-demographics } \\
\hline Age & $1.02(0.97-1.08)$ & $1.01(0.94-1.08)$ & $1.00(0.97-1.02)$ & $1.03(0.93-1.15)$ \\
\hline \multicolumn{5}{|l|}{ Year of study } \\
\hline 1 st & 1.00 & 1.00 & 1.00 & 1.00 \\
\hline $2 \mathrm{nd} / 3 \mathrm{rd}$ & $1.42(0.89-2.27)$ & $1.32(0.77-2.24)$ & $1.57(0.78-3.16)$ & $1.46(0.63-3.40)$ \\
\hline$\geq 4$ th & $1.50(0.85-2.67)$ & $1.63(0.83-3.20)$ & $4.36(1.93-9.83)^{*}$ & $3.93(1.45-10.67)^{\dagger}$ \\
\hline \multicolumn{5}{|l|}{ Family background } \\
\hline Poorer & 1.00 & & 1.00 & \\
\hline Wealthier & $0.80(0.54-1.19)$ & & $1.33(0.76-2.34)$ & \\
\hline \multicolumn{5}{|l|}{ Substance use } \\
\hline Current tobacco use & $2.29(1.40-3.74)^{*}$ & $1.51(0.85-2.66)$ & $12.78(3.12-47.52)^{*}$ & $3.26(0.52-20.59)$ \\
\hline Cannabis use in preceding month & $1.66(0.97-2.85)$ & & $8.25(2.65-25.72)^{*}$ & $6.15(1.27-29.80)^{\ddagger}$ \\
\hline \multicolumn{5}{|l|}{ Mental health } \\
\hline Screened positive for depression & $1.12(0.75-1.67)$ & & $1.13(0.64-1.99)$ & \\
\hline Screened positive for PTSD & $1.65(1.03-2.65)^{\ddagger}$ & $1.82(1.06-3.11)^{\ddagger}$ & $1.54(0.84-2.83)$ & \\
\hline \multicolumn{5}{|c|}{$\begin{array}{l}\mathrm{OR}=\text { odds ratio } \mathrm{CI}=\text { confidence interval; } \mathrm{AUDIT}=\text { alcohol use disorders identification test } \mathrm{PTSD}=\text { post } \text {-traumatic stress disorder. } \\
t p<0.001 . \\
p<0.01 .\end{array}$} \\
\hline
\end{tabular}


prevalence of trauma experiences was not as high as in some previous studies in SA. ${ }^{[23,34]}$

Regarding traumatic experiences, the study did not find gender differences in physical partner violence, sexual partner violence and physical abuse as a child, yet sexual abuse as a child was significantly more common among female than male university students. Gender symmetry in intimate partner violence seems to conform to the most recent findings of the international student dating violence study, where both sexes reported similar rates of havong been victims of dating violence. ${ }^{[35]}$ However, other previous studies, including studies done in SA, ${ }^{[36-38]}$ showed that suffering physical and sexual violence seemed to be more common among women than among men. This study only assessed minor and not severe physical partner violence, and it is possible that women under-reported minor physical partner violence, as found in some other studies, ${ }^{[39]}$ including the SA university student sample of the international student dating violence study. ${ }^{[35]}$ Cercone et al ${ }^{[40]}$ found that dating intimate partner violence is generally symmetrical at a topographical level, although significantly more women than men reported perpetration of severe physical assault.

Lifetime experiences of violence were found to be associated with depression and PTSD, as has been found among patrons of alcoholserving venues in Cape Town. ${ }^{[23]}$ Reported experiences of forced sex and sexual partner violence were associated with PTSD and depression in both men and women, as also found in a previous study in Cape Town. ${ }^{[23]}$ Among women, but not among men, a history of sexual abuse as a child was associated with PTSD, but not depression. For both women and men, a history of physical abuse as a child was associated with PTSD and only for men it was associated with depression.

The study found that poor mental health, including substance use, was associated with HIV risk behaviour among this sample of SA university students. This finding concurs with previous studies among university students. ${ }^{[16-21]}$ PTSD symptomatology and hazardous or harmful alcohol use were important predictors of HIV risk behaviour for men, and cannabis use was a significant predictor for women. While associations between alcohol use, ${ }^{[15-20]}$ drug use ${ }^{[19,20]}$ and HIV risk behaviours have previously been found among university students, the mechanisms explaining the association between alcohol use and HIV risk behaviours in this setting are not fully understood. ${ }^{[15]}$ Hazardous or harmful drinking and binge drinking seem to be associated in particular with indiscriminate forms of risky sex (e.g. having multiple or casual sex partners), which is in keeping with studies of American college populations. ${ }^{[41,42]}$ Weinhart and Carey ${ }^{[43]}$ suggest that, 'People who use alcohol more heavily may also be more likely to engage in more sexual risk behaviour because of a specific personality trait, or a constellation of attitudes and beliefs, rather than because of a unique relationship between alcohol use and sexual risk behaviour.'

Likewise, cannabis use (among women) was found to be associated with HIV risk behaviour, which conforms with several studies. ${ }^{[42,44,45]}$ This study did not find depressive symptomatology to be a predictor of HIV risk behaviour, as found in some other studies. ${ }^{[14,15]}$ Further, among women, being in the fourth or more year of study was associated with HIV risk behaviour. It is possible that at the point at which they are completing university education, women are more likely in a steady relationship and thus more likely to engage in HIV risk behaviour. ${ }^{[46]}$ Overall, poor mental health, traumatic experiences, and substance use may interact synergistically to increase HIV risk behaviour. ${ }^{[23]}$

\section{Study limitations}

Those seeking to generalise from this study's results should interpret them cautiously, as only full-time undergraduate students between the ages of 18 and 41 years were included in this study in a conveniently selected sample. It is unknown to what extent these findings can be generalised to part-time or non-resident students. The data used were obtained by self-report and could have been influenced by participants' desired responses. Although the study was anonymous, the sensitive nature of the items related to illegal drug use (cannabis) could have affected participants' responses. Moreover, this study was based on data collected in a cross-sectional survey. We cannot, therefore, ascribe causality to any of the associated factors in the study. A further limitation was that certain mental-health measures were made with brief screenings and may be interpreted only as indicators of poor mental health. ${ }^{[23]}$ In addition, the study did not screen for a history of severe mental illess, which has been found to be associated with HIV risk behaviour; ${ }^{[47]}$ this should be accounted for in future studies.

\section{Conclusion}

High rates of depression, PTSD, hazardous or harmful drinking and HIV risk behaviour were found among the studied university student population. Poor mental health, including substance use, was associated with HIV risk behaviour. Co-ordinated mental health and sexual and reproductive health services to meet the needs of university students would be desirable.

Acknowledgements. The sudy was funded by the Directorate General for Development Cooperation (DGDC) through the Flemish Interuniversity council (VLIR-UOS).

\section{Conflict of interest. None.}

\section{References}

1. Shisana O, Rehle T, Simbayi L, et al, the SABSSM III Implementation Team. South African National HIV Prevalence, Incidence, Behaviour and Communication Survey 2008: A Turning Tide Among Teenagers? Cape Town: HSRC Press, 2009.

2. National Department of Health, SA. The National Antenatal Sentinel HIV and Syphilis Prevalence Survey, South Africa, 2010. Pretoria: National Department of Health, 2011.

3. Patel V. Mental health in low- and middle-income countries. Br Med Bull 2007;81-82(1):81-96. [http://dx.doi.org/10.1093/bmb/ldm010]

4. Ciesla JA, Roberts JE. Meta-analysis of the relationship between HIV infection and risk for depressive disorders. Am J Psychiatry 2001;158(5):725-730. [http://dx.doi.org/10.1176/appi. ajp.158.5.725]

5. Myer L, Seedat S, Stein DJ, Moomal H, Williams DR. The mental health impact of AIDSrelated mortality in South Africa: A national study. J Epidemiol Community Health 2009;63(4):293-298. [http://dx.doi.org/10.1136/jech.2008.080861].

6. Crepaz N, Marks G. Are negative affective states associated with HIV sexual risk behaviors? A meta-analytic review. Health Psychol 2001;20(4):291-299. [http://dx.doi.org/10.1037/02786133.20.4.291]

7. Rehm J, Shield KD, Joharchi N, Shuper PA. Alcohol consumption and the intention to engage in unprotected sex: Systematic review and meta-analysis of experimental studies. Addiction 2012;107(1):51-59. [http://dx.doi.org/10.1111/j.1360-0443.2011.03621.x]

8. Rabkin JG. HIV and depression: 2008 review and update. Curr HIV/AIDS Rep 2008;5(4):163-171.

9. Lloyd S, Operario D. HIV risk among men who have sex with men who have experienced childhood sexual abuse: Systematic review and meta-analysis. AIDS Educ Prev 2012;24(3):228-241. [http://dx.doi.org/10.1521/aeap.2012.24.3.228]

10. Chersich MF, Rees HV. Causal links between binge drinking patterns, unsafe sex and HIV in South Africa: It's time to intervene. Int J STD AIDS 2010;21(1):2-7. [http://dx.doi.org/10.1258/ ijsa.2000.009432] 


\section{fre

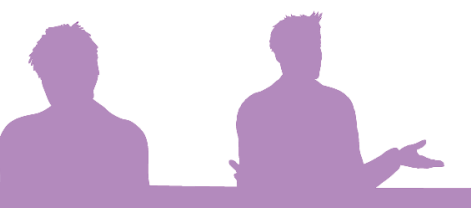

11. Pithey A, Parry C. Descriptive systematic review of Sub-Saharan African studies on the association between alcohol use and HIV infection. SAHARA J 2009;6(4):155-169.

12. Kalichman SC, Simbayi LC, Kaufman M, Cain D, Jooste S. Alcohol use and sexual risks for HIV/AIDS in sub-Saharan Africa: Systematic review of empirical findings. Prev Sci 2007;8(2):141-151. [http://dx.doi.org/10.1007/s11121-006-0061-2]

13. Wyatt GE, Myers HF, Loeb TB. Women, Trauma, and HIV: An overview. AIDS Behav 2004;8(4):401-403. [http://dx.doi.org/10.1007/s10461-004-7324-3]

14. Agardh A, Cantor-Graae E, Ostergren PO. Youth, sexual risk-taking behavior, and mental health: A study of university students in Uganda. Int J Behav Med 2012;19(2):208-216. [http:// dx.doi.org/10.1007/s12529-011-9159-4]

15. Lundberg P, Rukundo G, Ashaba S, et al. Poor mental health and sexual risk behaviours in Uganda: A cross-sectional population-based study. BMC Public Health 2011;11:125. [http:// dx.doi.org/10.1186/1471-2458-11-125]

16. Kim J, Celentano DD, Crum RM. Alcohol consumption and sexually transmitted disease risk behavior: Partner mix among male Korean university students. Alcohol Clin Exp Res 1998;22(1):126-131. [http://dx.doi.org/10.1111/j.1530-0277.1998.tb03626.x]

17. Griffin JA, Umstattd MR, Usdan SL. Alcohol use and high-risk sexual behavior among collegiate women: A review of research on alcohol myopia theory. J Am Coll Health 2010;58(6):523-532. [http://dx.doi.org/10.1080/07448481003621718]

18. Umoh OO, Umoh UJ. Alcohol related problems, family type and youth HIV/AIDS risk behaviour. Afr J Drug Alcohol Studies 2011;10(1):49-58.

19. Hoque ME. Reported risky sexual practices amongst female undergraduate students in KwaZulu-Natal, South Africa. Afr J Prm Health Care Fam Med 2011;3(1). [http://dx.doi.org/10.4102/phcfm.v3i1.281]

20. Adefuye AS, Abiona TC, Balogun JA, Lukobo-Durrell M. HIV sexual risk behaviors and perception of risk among college students: Implications for planning interventions. BMC Public Health 2009;9:281. [http://dx.doi.org/10.1186/1471-2458-9-281].

21. Agardh A, Odberg-Pettersson K, Ostergren PO. Experience of sexual coercion and risky sexual behavior among Ugandan university students. BMC Public Health 2011;11:527. [http://dx.doi org/10.1186/1471-2458-11-527].

22. Collings SJ. Childhood sexual abuse in a sample of South African university males Prevalence and risk factors. S Afr J Psychol 1991;21(3):153-158. [http://dx.doi. org/10.1177/008124639102100304]

23. Sikkema KJ, Watt MH, Meade CS, et al. Mental health and HIV sexual risk behavior among patrons of alcohol serving venues in Cape Town, South Africa. J Acquir Immune Defic Syndr 2011;57(3):230-237. [http://dx.doi.org/10.1097/QAI.0b013e3182167e7a]

24. Kimerling R, Ouimette P, Prins A, et al. Brief report: Utility of a short screening scale for DSM IV PTSD in primary care. J Gen Intern Med 2006;21(1):65-67. [http://dx.doi.org/10.1111/ j.1525-1497.2005.00292.x]

25. Andresen EM, Malmgren JA, Carter WB, Patrick DL. Screening for depression in well older adults: Evaluation of a short form of the CES-D (Center for Epidemiologic Studies Depression Scale). Am J Prev Med, 1994;10(2):77-84.

26. Mulrow CD, Williams JW Jr, Gerety MB, et al. Case-finding instruments for depression in primary care settings. Ann Intern Med 1995;122(12):913-921.

27. Babor TF, Higgins-Biddle JC. Brief Intervention for Hazardous and Harmful Drinking: A Manual for Use in Primary Care. Geneva, Switzerland: World Health Organization Department of Mental Health and Substance Dependence, 2001.

28. Freeborn DK, Polen MR, Hollis JF, Senft RA. Screening and brief intervention for hazardous drinking in an HMO: Effects on medical care utilization. J Behav Health Serv Res 2000;27(4):446-453.
29. Reid MC, Fiellin DA, O'Connor PG. Harzardous and harmful alcohol consumption in primary care. Arch Inter Med 1999;159(15):1681-1689.

30. Kalichman SC, Simbayi L, Jooste S, Vermaak R, Cain D. Sensation seeking and alcohol use predict HIV transmission risks: Prospective study of sexually transmitted infection clinic patients, Cape Town, South Africa. Addict Behav 2008;33(12):1630-1633. [http://dx.doi. org/10.1016/j.addbeh.2008.07.020]

31. Peltzer K, Simbayi L, Kalichman S, et al. Drug use and HIV-risk behaviour in three urban South African communities. J Soc Sci 2009;18(2):143-149.

32. Smit J, Myer L, Middelkoop K, et al. Mental health and sexual risk behaviours in a South African township: A community-based cross-sectional study. Public Health 2006;120(6):534542. [http://dx.doi.org/10.1016/j.puhe.2006.01.009]

33. Peltzer K, Ramlagan S, Chirinda W, Mlambo G, McHunu G. A community-based study to examine the effect of a youth HIV prevention programme in South Africa. Int J STD AIDS 2012;23(9):653-658. [http://dx.doi.org/10.1258/ijsa.2012.011457]

34. Kaminer D, Grimsrud A, Myer L, Stein DJ, Williams DR. Risk for post-traumatic stress disorder associated with different forms of interpersonal violence in South Africa. Soc Sci Med 2008;67(10):1589-1595. [http://dx.doi.org/10.1016/j.socscimed.2008.07.023]

35. Straus MA. Dominance and symmetry in partner violence by male and female university students in 32 nations. Children Youth Serv Rev 2008;30:252-275. [http://dx.doi.org/10.1016/j. childyouth.2007.10.004]

36. Cáceres C, Vanoss MB, Sid HE. Sexual coercion among youth and young adults in Lima, Peru. J Adolesc Health 2000;26(5):361-367.

37. Jewkes R, Abrahams N. The epidemiology of rape and sexual coercion in South Africa: An overview. Soc Sci Med 2002;55(7):1231-1244

38. Gass JD, Stein DJ, Williams DR, Seedat S. Gender differences in risk for intimate partne violence among South African adults. J Interpers Violence 2011;26(14):2764-2789. [http:// dx.doi.org/10.1177/0886260510390960]

39. Dobash RP, Dobash RE. Women's violence to men in intimate relationships: Working on a puzzle. Br J Criminol 2004;44(3):324-349. [http://dx.doi.org/10.1093/bjc/azh026]

40. Cercone JJ, Beach SR, Arias I. Gender symmetry in dating intimate partner violence: Does similar behavior imply similar constructs? Violence Vict 2005;20(2):207-218.

41. Cooper ML. Alcohol use and risky sexual behavior among college students and youth: Evaluating the evidence. J Stud Alcohol Suppl 2002;14:101-117.

42. Howard DE, Wang MQ. The relationship between substance use and STD/HIV-related sexual risk behaviors among U.S. adolescents. J HIV/AIDS Prev Children \& Youth 2004;6(2):65-82.

43. Weinhardt LS, Carey MP. Does alcohol lead to sexual risk behavior? Findings from event-level research. Annu Rev Sex Res 2000;11:125-157.

44. Brodbeck J, Matter M, Moggi F. Association between cannabis use and sexual risk behavior among young heterosexual adults. AIDS Behav 2001;10(5):599-605. [http://dx.doi. org/10.1007/s10461-006-9103-9].

45. Castilla J, Barrio G, Belza MJ, de la Fuente L. Drug and alcohol consumption and sexual risk behaviour among young adults: Results from a national survey. Drug Alcohol Dependency 1999;56(1):47-53.

46. Heeren GA, Jemmott JB 3rd, Mandeya A, Tyler JC. Sub-Saharan African university students' beliefs about condoms, condom-use intention, and subsequent condom use: A prospective study. AIDS Behav 2009,13(2):268-276. [http://dx.doi.org/10.1007/s10461-008-9415-z]

47. Meade CS, Sikkema KJ. HIV risk behavior among adults with severe mental illness: A systematic review. Clin Psychol Rev 2005;25(4):433-457. [http://dx.doi.org/10.1016/j. cpr.2005.02.001] 